\title{
Early-Onset Familial Alzheimer's Disease (EOFAD)
}

\author{
Liyong Wu, Pedro Rosa-Neto, Ging-Yuek R. Hsiung, A. Dessa Sadovnick, \\ Mario Masellis, Sandra E. Black, Jianping Jia, Serge Gauthier
}

\begin{abstract}
Early-onset familial Alzheimer's disease (EOFAD) is a condition characterized by early onset dementia (age at onset $<65$ years) and a positive family history for dementia. To date, 230 mutations in presenilin (PS1, PS2) and amyloid precursor protein (APP) genes have been identified in EOFAD. The mutations within these three genes (PS1/PS2/APP) affect a common pathogenic pathway in APP synthesis and proteolysis, which lead to excessive production of amyloid $\beta$. Compared with sporadic Alzheimer's disease (AD), EOFAD has some distinctive features including early age at onset, positive familial history, a variety of non-cognitive neurological symptoms and signs, and a more aggressive course. There is marked phenotypic heterogeneity among different mutations of EOFAD. Studies in presymptomatic mutation carriers reveal biomarkers abnormalities. EOFAD diagnosis is based on clinical and family history, neurological symptoms and examination, biomarker features, as well as genotyping in some cases. New therapeutic agents targeting amyloid formation may benefit EOFAD individuals.
\end{abstract}

\begin{abstract}
RÉSUMÉ: La maladie d'Alzheimer familiale à début précoce. La maladie d'Alzheimer familiale à début précoce (MAFDP) est une maladie caractérisée par une démence à début précoce (âge de début $<65$ ans) et une histoire familiale de démence. À ce jour, 230 mutations dans les gènes des présélinines (PS1, PS2) et du précurseur de la protéine amyloïde (APP) ont été identifiées dans la MAFDP. Des mutations de ces 3 gènes (PS1, PS2, APP) touchent une voie pathogène commune dans la synthèse et la protéolyse de l'APP, ce qui entraîne la production excessive de protéine $\beta$-amyloïde. La MAFDP comporte des caractéristiques distinctes de la MA sporadique, dont un âge de début précoce, une histoire familiale positive, des symptômes et des signes neurologiques non cognitifs variés et une évolution plus rapide de la maladie. Il existe beaucoup d'hétérogénéité phénotypique parmi les différentes mutations dans la MAFDP. Des études effectuées chez des porteurs de mutations avant l'apparition des symptômes ont monté la présence d'anomalies au niveau de certains biomarqueurs. Le diagnostic de la MAFDP est basé sur l'histoire clinique et l'histoire familiale, les symptômes neurologiques et l'examen neurologique, les biomarqueurs et le génotypage chez certains cas. De nouveaux agents thérapeutiques qui ciblent la production de l'APP pourraient s'avérer utiles chez les individus atteints de MAFDP.
\end{abstract}

Can J Neurol Sci. 2012; 39: 436-445

Early-onset familial Alzheimer's disease (EOFAD) is a condition characterized by dementia onset at a relatively young age (before 65 years of age) and a positive family history for dementia. Multiple terminologies such as familial Alzheimer's disease $(\mathrm{FAD})^{1}$, early-onset AD (EOAD) ${ }^{2}$, autosomal dominant $\mathrm{AD}$ (ADAD), and autosomal dominant forms of early-onset AD $(\mathrm{ADEOAD})^{3}$ have been used to describe similar but overlapping entities. We summarize the complex nosology in Figure 1.

Diagnostic criteria have a tremendous impact on the EOFAD epidemiology. If we use the stringent criteria of EOAD as onset of disease at age $<61$ years, and ADEOAD as occurrence of EOAD in at least three generations, the prevalence of EOAD and ADEOAD are 41.2 and 5.3 per 100,000 persons, respectively. ${ }^{3}$ This variable nosology poses a substantive challenge in identifying cases that should undergo predictive genetic testing in asymptomatic individuals for mutations in one of the three identified Alzheimer's disease (AD)-related causal genes, since the priori probability of having a positive hit will be dependent on the definition used. Here, we will use EOFAD throughout this paper and use the onset criteria of age $<65$ years.

From the McGill Centre for Studies in Aging (MCSA) (LW, PRN, SG), Translational Neuroimaging Laboratory (LW, PRN), Douglas Research Institute, McGill University; McConnell Brain Imaging Centre (PRN), Montreal Neurological Institute, Montreal, QC; Division of Neurology (GYRH, ADS), Faculty of Medicine, Department of Medical Genetics (ADS), University of British Columbia, Vancouver, BC; Department of Medicine (Neurology) (MM, SEB), Brain Sciences Research Program, Sunnybrook Health Sciences Centre, Neurogenetics Section (MM), Centre for Addiction and

Mental Health, University of Toronto, Toronto, ON, Canada; Department of Neurology (LW, JJ), Xuan Wu Hospital, Capital Medical University, Beijing, China

Received December 8, 2011. Final Revisions Submitted January 30, 2012. Correspondence to: Serge Gauthier, McGill Centre for Studies in Aging (MCSA), McGill University, 6825, Boul. LaSalle Blvd., Montreal, QC, H4H 1R3, Canada. Email: serge.gauthier@mcgill.ca 


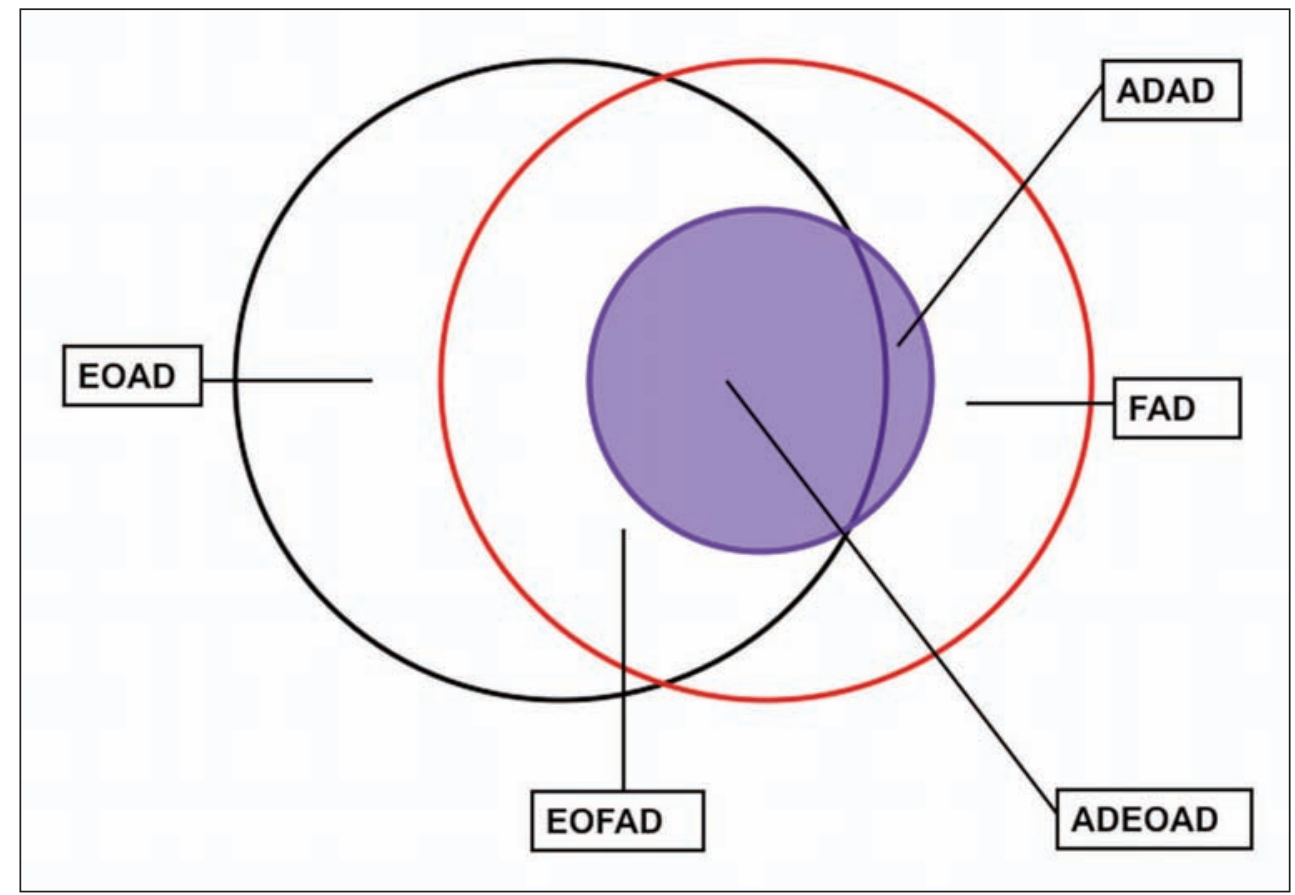

Figure 1: Diagram representing the relationship between several terms about $A D$. Red circle: familial $A D$ $(F A D)$; black circle: early-onset $A D$ (EOAD); blue circle and shadow: autosomal dominant $A D$ $(A D A D)$.The area surrounded by red and black line represent early onset familial $A D(E O F A D)$. The region encircled by blue and black line is autosomal dominant form of early-onset $A D(A D E O A D)$.

Early-onset familial Alzheimer's disease represents up to 5\% of the $\mathrm{AD}$ cases assessed in memory clinics and encompasses at least 230 mutations in three genes coding, or molecular processes involving the synthesis and proteolysis of betaamyloid peptide ${ }^{4}$ (http://www.molgen.ua.ac.be/ADMutations). Almost $50 \%$ of individuals carrying mutations in the presenilins (PS1 and PS2) and amyloid precursor protein (APP) genes have been identified in family pedigrees compatible with an autosomal dominant form of EOFAD. ${ }^{4-6}$

Mutation in one of these three genes is, to date, the only deterministic factor for AD. Thus, study of EOFAD patients and their families is of paramount importance for understanding the mechanisms underlying progression from "no cognitive impairment" to "dementia"? In addition, because of nearly $100 \%$ penetrance, longitudinal observational studies of EOFAD mutations carriers will provide the complete clinical course of $\mathrm{AD}$ progression from pre-clinical, mild cognitive impairment (MCI) and eventually to dementia phases. ${ }^{8-10}$ The goal of the present review paper is to summarize the current state of knowledge on EOFAD.

\section{Genetic mutations}

The high incidence of AD-like clinical and neuropathological changes in older patients with Down syndrome (trisomy 21) led to the suggestion that the causative gene of familial AD may be located on chromosome $21 .{ }^{11}$ In 1987 , a gene locus at 21q11.2 to 21q22.2 was found in four large ADAD families by genetic linkage study. ${ }^{11}$ In 1991, the first missense mutation (Val $\rightarrow$ Ile) in $A P P$ was reported on chromosome $21 \mathrm{p} 2$ in one single EOFAD family, thus providing the first possible association between the $A P P$ mutations and abnormalities in amyloid processing. ${ }^{12}$ Since several families with early onset $\mathrm{AD}$ had no linkage to chromosome 21, Goate et al suggested that genetic heterogeneity may exist within EOFAD. ${ }^{12}$ Genetic heterogeneity was further supported by several independent studies when a locus for EOFAD on 14q24 was identified in $1992 . .^{13-15}$ In 1995, the PSI gene, which encodes the protein presenilin 1 required for $\gamma$ secretase to produce amyloid-beta (A $\beta$ ) from APP, was cloned for the first time and was identified as one of pathogenic genes for the EOFAD. ${ }^{16}$ In the same year, the missense mutation in PS2 was found on the long arm of chromosome 1 in two different studies. ${ }^{17,18}$

To date, approximately 185 different pathogenic mutations in $P S 1,13$ mutations in $P S 2$ and 32 mutations (or gene duplication) in APP have been identified in EOFAD (http://www.molgen. ua.ac.be/ADMutations). Nearly half of the families fulfilling criteria for EOFAD harbor one of these mutations. The underlying genetic defect remains unknown for the remaining $50 \%$ of EOFAD cases, suggesting further genetic and/or etiologic heterogeneity. ${ }^{19,20}$

While PS1 mutations are responsible for nearly $75-80 \%$ of genotyped families positive for a mutation, $A P P$ and $P S 2$ mutations are responsible for $20-15 \%$ and less than $5 \%$, respectively..$^{3-5}$ The majority of the presenilin mutations are single-nucleotide substitutions, but small deletions and insertions have been described as well (http://www.molgen. ua.ac.be/ADMutations). Mutations of $P S 1$ and $P S 2$ cause amino acid sequence changes throughout the protein with some 


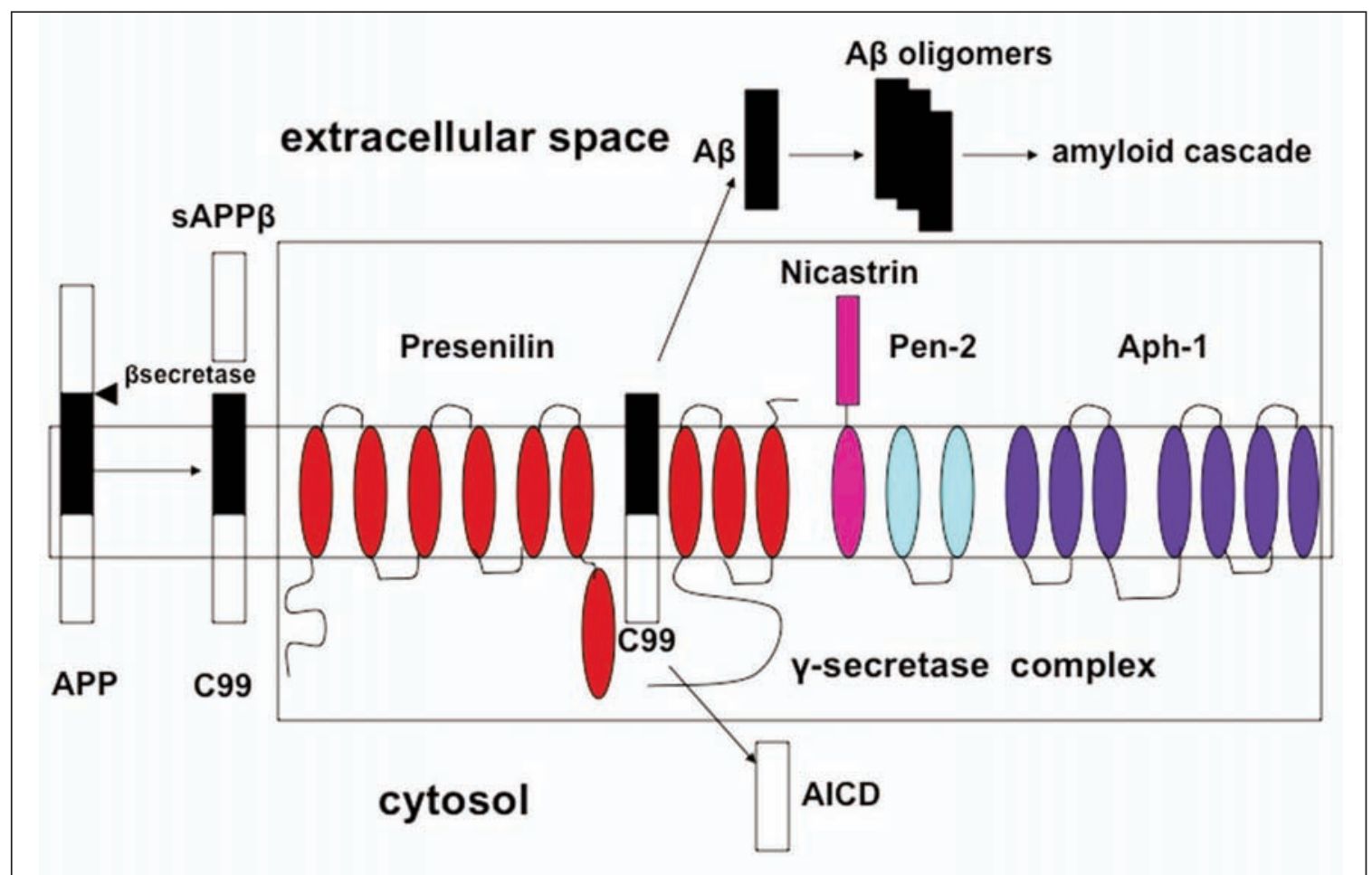

Figure 2: Schematic illustration of amyloidogenic proteolytic pathway. The amyloidogenic pathway starts with $\beta$-secretase cleavage of APP, yielding SAPP $\beta$ and C99. C99 follows further $\gamma$-secretase complex proteolysis yielding AICD in cytosol and soluble $A \beta$ peptide (predominately $A \beta 42$ and $A \beta 40$ ) in the extracellular space. The $\gamma$-secretase complex comprises of presenilin, nicastrin, pen-2 and aph-1. Cleavage of C99 occurs in the active site of presenilin. A $\beta$ monomers subsequently aggregate in the extracellular space to form soluble oligomers, and eventually deposit into insoluble amyloid plaques, starting a cascade of down-stream pathological processes. Abbreviation: APP-amyloid precursor protein, sAPP $\beta$-soluble amyloid precursor protein $\beta$ production, AICD-amyloid intracellular domain, C99-C-terminal fragment of 99 amino acids in the membrane.

clustering within the transmembrane domains and the hydrophilic loops. Seventy-five percent of APP mutations are missense and are located within exons 16 and 17 near the $\beta$ - and $\gamma$-secretase cleavage sites. The remaining $25 \%$ of APP mutations are duplications rather than missense mutations (http://www.molgen.ua.ac.be/ADMutations).

\section{Pathophysiology}

Although the amyloid cascade is only one theory among myriads of other possible mechanisms for AD (e.g. tau, inflammatory or oxidative stress hypothesis) and amyloid alone is probably not sufficient to cause $\mathrm{AD}$, the association of $P S 1 / P S 2 / A P P$ with amyloid synthesis and its processing warrants the amyloid cascade theory plays a more important role in EOFAD than the sporadic AD. ${ }^{21-24}$ According to the amyloid cascade hypothesis, $\mathrm{AD}$ is a consequence of an imbalance between $\mathrm{A} \beta$ production and $\mathrm{A} \beta$ clearance. ${ }^{24}$ In EOFAD, PS1, $P S 2$ or APP mutations all have a common pathogenic mechanism resulting in increased production of $\mathrm{A} \beta 42 .{ }^{25}$

Missense or duplication mutations in $A P P$ frequently increase the level of $A \beta 42 .{ }^{26} A P P$ mutations near the $\beta$-secretase cleavage site augment $\beta$-site proteolysis leading to elevation of both $\mathrm{A} \beta 40$ and $A \beta 42 .{ }^{27}$ In contrast, those near the $\gamma$-secretase cleavage site increase production of $\mathrm{A} \beta 42 .{ }^{28}$
As shown in Figure 2, presenilins are part of the catalytic subunit of the $\gamma$-secretase complex and are functionally involved in the $\gamma$-secretase-mediated proteolytic cleavage of APP. ${ }^{26,29}$ Mutations in PS1 or PS 2 change the cleavage activity of APP, resulting in increased $A \beta 42$ production with high $A \beta 42 / A \beta 40$ ratio. ${ }^{26,29}$ It has been suggested that increased toxic $A \beta 42$ initiates a cascade of down-stream pathological processes such as tau hyperphosphorylation, neurofibrillary tangles (NFTs) formation, neuroinflammation, loss of synaptic junctions and neuronal cell death, with dementia being the ultimate clinical result of these progressive neurodegenerative processes. ${ }^{24}$

\section{Neuropathology}

Early-onset familial Alzheimer's disease exhibits the classic hallmark neuropathology of sporadic $\mathrm{AD}$, including amyloid plaques, NFTs, neuronal loss and tissue atrophy, often in significantly enhanced quantities. ${ }^{30}$ For example, EOFAD is linked to significantly higher amounts of amyloid deposition compared with sporadic AD. ${ }^{30,31}$ Furthermore, some cases of EOFAD have been shown to have a faster rate of NFTs formation, neuronal loss and atrophy compared to sporadic AD. ${ }^{31,32}$

In contrast with sporadic $\mathrm{AD}$, certain EOFAD mutations are characterized by distinctive neuropathological features, 
including cotton wool plaques (CWP), severe cerebral amyloid angiopathy (CAA), or the presence of Lewy bodies. ${ }^{30,31}$ On the other hand, variable pathological expression reported in individuals carrying the same mutation suggests that epigenetic or other genetic factors may play a role in this phenotypic heterogeneity. ${ }^{33}$ It should be emphasized that there is considerable neuropathological heterogeneity across different $A P P$ and $P S$ mutations. ${ }^{32,34}$

As a variant of the amyloid plaque, CWP consist of large balllike $A \beta$ (mainly $A \beta 42$ ) deposits, usually devoid of a dense amyloid core or neuritic pathology. ${ }^{35,36}$ Cotton wool plaques are most often reported in PS1 mutations affecting exons 8 and 9, but are also observed in mutations of other regions in $P S 1.30,37,38$ Up to 2009, 30 families with 25 defined PS1 mutations have been identified with CWP pathology. ${ }^{30}$ Cotton wool plaques variants often present with a particular clinical phenotype including spastic paraparesis and early onset (usually before 50 years-old) dementia. ${ }^{35,36,38}$

In addition to amyloid deposition, CAA in the leptomeninges and penetrating vessels of the cortex and cerebellum is a pathological feature of many cases with APP mutations. ${ }^{30,39,40}$ Significant CAA is more frequently associated with PS1 mutations beyond codon 200, but a modest degree of CAA can be also found in other PS1 and PS2 mutations. ${ }^{32,41-44}$ Of note, A $\beta$ deposited in vessels in CAA is mainly $\mathrm{A} \beta 40$ rather than the more commonly observed $\mathrm{A} \beta 42 .^{30,43}$ In some $A P P$ mutation cases, CAA can cause cerebral hemorrhage or stroke, which can in fact be the dominant phenotype rather than dementia itself. ${ }^{45,46}$

As reported in sporadic AD, Lewy body pathology composed of $\alpha$-synuclein has also been found in the amygdala, substantia nigra, and even neocortex in some PS1 and PS2 mutations carriers. ${ }^{42,47,48}$ Lewy bodies coexist with CWP, suggesting that PS1 may also play an important role in the pathogenetic process of both aggregation of $\alpha$-synuclein into Lewy bodies and deposition of $\beta$-amyloid into CWP48.

\section{Clinical features}

\subsection{Clinical features of EOFAD}

Similar to sporadic AD, most EOFAD cases have insidious onset episodic memory symptoms followed by other cognitive impairments. ${ }^{7}$ However, EOFAD has distinctive features including early age at onset (AAO) as well as non-cognitive neurological symptoms and a more aggressive course..$^{1,49}$

Age at onset is a robust clinical feature of EOFAD compared to the sporadic AD. ${ }^{50}$ One study demonstrated that the mean AAO of EOFAD was 46.9 years with the age ranging from 33 to 60 years. ${ }^{5,42}$ In general, the AAO of the autosomal dominant cases is earlier than that of the familial non-autosomal dominant cases. ${ }^{4}$ In addition, pedigrees with PS1 mutations have an earlier mean AAO compared to those with APP or PS2 mutations. ${ }^{50}$ In contrast to families with $A P P$ and $P S 2$ mutations, the presence of one or two APOE e4 alleles does not have an effect on the AAO in families carrying PS1 mutations. ${ }^{32,51}$

It is thought that EOFAD has a more aggressive course than late-onset sporadic $\mathrm{AD}$, and EOFAD is associated with faster cognitive decline and higher mortality ${ }^{52}$ In addition to memory impairment, patients with EOFAD often present with prominent cognitive impairment in other domains, such as apraxia, aphasia, or dysexecutive syndrome. ${ }^{53}$ It has also been described that
EOFAD patients may have myoclonus, seizures, spastic paraparesis, and extrapyramidal signs more frequently than sporadic AD. ${ }^{32,54-59}$ Cerebral hemorrhage or stroke is a characteristic feature probably related to extensive CAA in some EOFAD cases, especially in APP mutation carriers. ${ }^{46,60}$ It should be noticed that there is considerable phenotypic heterogeneity among all affected family members within a pedigree..$^{33,47}$

\subsection{Clinical features according to genotype}

The clinical features of EOFAD are heterogeneous, most probably due to different genetic mutations and epigenetic factors. ${ }^{55}$ We summarize the clinical features according to different genotypes in the following section (Table).

\subsubsection{Clinical spectrum of PS1 mutations}

Early-onset familial Alzheimer's disease with PS1 mutations typically have an AAO in the early 40s, ranging from 24 to 65 years. ${ }^{31,32,61}$ Among 21 cases of EOFAD caused by PS1 mutations (in intron 4), mean AAO is 37.4 years, mean age at death is 44.7 years and mean duration of illness is 7.3 years. ${ }^{62} \mathrm{~A}$ large scale follow-up study of PS1 E280A mutation carriers examining the whole spectrum of clinical progression from asymptomatic to dementia stages showed that median AAO was 38 years for symptomatic pre-MCI (which is defined by the present of memory complaints without meeting the criteria of MCI), 44 years for MCI, and 49 years for dementia. ${ }^{63}$ When the $\mathrm{AAO}$ of $\mathrm{AD}$ is before 35 years old, this disease is usually defined as very early onset Alzheimer disease (VEOAD) ${ }^{64}$ A literature review disclosed a total of 101 cases of VEOAD from 1934 to $2007^{64}$, with all for whom conclusive genetic analysis have been done showing PS1 mutations. ${ }^{42,64-67}$

Very little has been published on the neuropsychological profile in EOFAD with PS1 mutations. ${ }^{63,68}$ Although a subcortical pattern of neuropsychological deficits has been noted in some case reports, the cognitive profile has so far predominantly shown amnestic and involved multiple domains. ${ }^{63,68}$ In addition to cognitive symptoms, EOFAD with PS1 mutations may present with some unusual clinical features, in particular myoclonus and seizures. ${ }^{62}$ Despite almost all these symptoms having been reported in sporadic $\mathrm{AD}$, extrapyramidal signs, behavioral and psychiatric symptoms (BPS) (anxiety, hallucinations, delusions), aphasia, visual agnosia, and ataxia are significantly more frequently found in in EOFAD with PS1 mutations. ${ }^{55,68-70}$

The best example of a specific phenotype associated with a PS1 mutation probably represents the syndrome of "variant AD". ${ }^{33}$ This syndrome is characterized by an early onset familial dementia and spastic paraparesis, typically associated with different $P S 1$ mutations in exons 8 and 9 , and unusual pathologic findings namely CWP. ${ }^{30,33,35,55,71}$ The mean AAO of this syndrome ranges from 27 to mid 50s, with the most typical being at the earlier ages of the spectrum. ${ }^{33,55}$ Thus, it is not surprising that many VEOFAD cases have been reported with this syndrome. ${ }^{38,42,72}$ Spastic paraparesis of this "variant AD" is characterized by insidiously progressive impaired gait and mild weakness in the lower limbs, with the signs of hyperreflexia and clonus. ${ }^{33,36}$ In most patients, the spastic paraparesis precedes the dementia but this is not always the case. . $^{33,36}$ 


\subsubsection{Clinical spectrum of PS2 mutations}

Of the three genes known to cause EOFAD, mutations in PS2 are the least common, and therefore the literature is relatively scant. ${ }^{4,18}$ Volga German pedigrees with N141I mutation in PS2 remain the largest and most studied group. ${ }^{18,58}$

Compared to PS1 mutation carriers, carriers with PS2 mutations have a later AAO, a relatively longer disease duration, and a more variable disease expression. ${ }^{58,73} \mathrm{~A}$ review of 101 Volga German cases with N141I mutation in PS2 showed a mean onset age in the 50s (53.7 7.8 years, range 39-75) and a disease duration of 10.6 years, longer than PS1 mutations (8.4 years) but similar to sporadic late onset AD (10.6 years). ${ }^{58}$ Segregation and linkage analysis in Volga Germans have shown that APOE plays a small but significant role in modifying the AAO, with evidence for a dose-dependent relationship between number of APOEe4 alleles and AAO.${ }^{51}$ Early and progressive defects in memory and executive functions are common with relative sparing of naming. ${ }^{58}$ PS2 mutations in this population are also more commonly associated with seizures (30\%), hallucinations, delusions or 'psychotic' features (32\%), and in some rare cases severe amyloid angiopathy and hemorrhagic stroke. ${ }^{58}$

Interestingly, in an Italian family with PS2 A85V mutation, the phenotypic information is very heterogeneous. The proband showed a clinical phenotype indicative of Lewy body dementia and an unusually neuropathologic feature characterized by the presence of abundant and widespread cortical Lewy bodies in addition to the hallmark pathologic lesions of $\mathrm{AD} .{ }^{47}$ In contrast, other affected family members exhibited a clinical phenotype typical of AD. ${ }^{44}$

\subsubsection{Clinical spectrum of APP mutations}

Among the 32 APP missense mutations families reported, the clinical symptoms for the Flemish mutation (A692G) ${ }^{74-76}$, Dutch mutation (E693Q $)^{77}$, Arctic mutation $(\mathrm{E} 693 \mathrm{G})^{78}$, and Iowa mutation (D694N) ${ }^{79}$ are the most well studied and described. The phenotype is heterogeneous among the various mutations. The mean AAO ranged from the 40 s (Flemish mutation) ${ }^{75}$ to 50 s or 60s (Iowa mutation) ${ }^{79}$. In comparison with PS1 and PS2 mutations carriers, $A P P$ mutation carriers typically display a more severe CAA pathology, which can lead to haemorrhage, stroke-like episodes, leukoencephalopathy, and even cortical calcification. ${ }^{75,76,78,79}$ Clinically, patients with the Flemish mutations present either with symptoms related to cerebrovascular events or with cognitive dysfunction; ${ }^{75,76}$ whereas the Dutch mutation is mainly characterized by haemorrhage, often but not always followed by cognitive impairment or dementia. ${ }^{80}$ Moreover, the clinical picture of the Iowa mutation is a progressive aphasic dementia and leukoencephalopathy without any apparent focal symptoms, but often with the presence of occipital calcifications. ${ }^{79}$ As for patients with the Arctic mutations, the clinical picture is multiple cognitive dysfunctions without haemorrhage, consistent with the typical spectrum of AD. ${ }^{78}$

In addition to $A P P$ mutations, $A P P$ duplication has been shown to be sufficient to cause EOFAD with CAA..$^{39,40,60,81}$ In a study of five families with EOFAD and CAA due to APP duplication, the neuropathological findings were similar to those of Down's syndrome patients. ${ }^{39}$ The cardinal clinical presentation is progressive dementia, frequently accompanied by intracerebral haemorrhage $(26 \%)$ and seizures $(57 \%) .{ }^{39}$ AAO of

Table: Clinical spectrum among different genotypes of EOFAD

\begin{tabular}{|c|c|c|c|}
\hline & PS1 mutations & PS2 mutations & $A P P$ mutations or duplication \\
\hline Frequency & $75-80 \%$ & $<5 \%$ & $20-15 \%$ \\
\hline $\begin{array}{l}\text { Mutations } \\
\text { reported }\end{array}$ & 185 & 13 & $\begin{array}{l}32 \text { mutations or complete gene } \\
\text { duplication }\end{array}$ \\
\hline Chromosome & 14 & 1 & 21 \\
\hline Pathophysiology & $\begin{array}{l}\text { increased } A \beta 42 \text { production and high } \\
A \beta 42 / A \beta 40 \text { ratio }\end{array}$ & $\begin{array}{l}\text { increased } A \beta 42 \text { production } \\
\text { and high } A \beta 42 / A \beta 40 \text { ratio }\end{array}$ & $\begin{array}{l}\text { increased production of } A \beta 42 \text { alone, } \\
\text { or both } A \beta 42 \text { and } A \beta 40\end{array}$ \\
\hline Pathology & CWP in some, mild CAA in most & no CWP & severe CAA in most \\
\hline Age at onset & $\begin{array}{l}\text { mean AAO at early forties, ranged } \\
\text { from } 24 \text { to } 65 \text { years }\end{array}$ & $\begin{array}{l}\text { mean AAO in fifties, range } \\
\text { from } 39 \text { to } 75 \text { years }\end{array}$ & $\begin{array}{l}\text { forties (Flemish mutation) to fifties } \\
\text { or sixties (Iowa mutation) }\end{array}$ \\
\hline Canonical & spastic paraparesis in some special & seizures, behavioural and & haemorrhage, stroke-like episodes \\
\hline Phenotype & $\begin{array}{l}\text { type; myoclonus, seizures, } \\
\text { extrapyramidal signs, behavioural } \\
\text { and psychiatric symptoms in some } \\
\text { cases }\end{array}$ & $\begin{array}{l}\text { psychiatric symptoms in } \\
\text { some }\end{array}$ & $\begin{array}{l}\text { and leukoencephalopathy associated } \\
\text { with severe CAA; seizures common }\end{array}$ \\
\hline Amyloid imaging & $\begin{array}{l}\text { increased PiB retention in striatum } \\
\text { and cortex }\end{array}$ & no literature available & $\begin{array}{l}\text { increased } \mathrm{PiB} \text { retention in the } \\
\text { striatum and cortex }\end{array}$ \\
\hline FDG-PET & $\begin{array}{l}\text { early hypometabolism in the } \\
\text { posterior cingulate cortices, } \\
\text { hippocampus and entorhinal cortices } \\
\text { in presyptomatic stage }\end{array}$ & no literature available & no literature available \\
\hline Structural MRI & $\begin{array}{l}\text { early medial temporal lobe atrophy } \\
\text { in the presyptomatic stage }\end{array}$ & no literature available & no literature available \\
\hline CSF & $\begin{array}{l}\text { profoundly decreased } A \beta 42 \text { and } \\
\text { increased t-tau and p-tau in } \\
\text { presymptomatic stage }\end{array}$ & no literature available & $\begin{array}{l}\text { profoundly decreased } A \beta 42 \text { and } \\
\text { increased t-tau and p-tau }\end{array}$ \\
\hline
\end{tabular}


dementia ranges from 42 to 59 years, intracerebral haemorrhage from 53 to 64 years and age at death from 46 to 75 years. ${ }^{39}$ It is not clear why there is such a high prevalence of seizures in patients with $A P P$ duplication but one could surmise that this might be due to cortical hemorrhages.

\section{Biomarker profile in EOFAD}

Due to nearly $100 \%$ penetrance in EOFAD mutation carriers, serial neuroimaging or cerebrospinal fluid (CSF) examination in the early stage of the mutation carriers provides an opportunity to identify early biomarkers of EOFAD that can be used to track disease progression from the presymptomatic stage through to dementia. ${ }^{82-84}$ Importantly, the study of EOFAD mutation carriers presents a nearly ideal scenario to test the amyloid cascade hypothesis and to study the effects of novel amyloid lowering therapies coming down the pipeline. ${ }^{85}$

A growing number of neuroimaging studies have demonstrated evidence of early alterations in brain structure and function in EOFAD mutations carriers prior to the onset of clinical symptoms. Pittsburgh Compound B (PiB) positron emission tomography (PET) studies have revealed evidence of elevated $\mathrm{PiB}$ retention beginning in the striatum in presymptomatic and early symptomatic PS1 and APP mutation carriers $^{86-88}$ as well as $A P P$ gene duplication cases $^{89}$, with neocortical areas becoming involved later. The pattern of amyloid deposition in EOFAD differs from that in sporadic AD, with higher striatal and somewhat lower cortical $\mathrm{PiB}$ retention in EOFAD ${ }^{86,88}$ However, in the early clinical course, striatal amyloid depositions in EOFAD are not typically associated with either extrapyramidal symptoms or altered cognitive status. ${ }^{86,87}$

Alterations in brain metabolism and function have also been reported among presymptomatic EOFAD carriers using [18F]fluorodeoxyglucose (FDG) PET and functional magnetic resonance imaging (MRI), respectively. ${ }^{90}$ Presymptomatic EOFAD individuals show widespread hypometabolism, consistent with the typical pattern seen in sporadic AD, involving the posterior cingulate cortex, hippocampus and entorhinal cortices, which precede significant brain atrophy in these regions. ${ }^{90}$ These data suggest that FDG-PET measures may serve as more sensitive biomarkers than structural MRI for the preclinical diagnosis of $\mathrm{AD}$. In one functional MRI study, presymptomatic PS1 mutation carriers exhibited increased activity in the right anterior hippocampus during a task of encoding of novel face-name associations compared to matched controls. ${ }^{83}$ Another task-induced functional MRI study demonstrated activation decline in anterior cingulate cortex in the presymptomatic PSI mutation carriers when employing an implicit novelty encoding paradigm. ${ }^{91}$

Structural MRI studies demonstrated that atrophy of the medial temporal lobe, including hippocampus and entorhinal cortex, was an early structural abnormality observed in presymptomatic and early symptomatic carriers, which can precede the clinical diagnosis of EOFAD by 3.5-5.5 years. ${ }^{82,84,92,93}$ Diffusion tensor imaging demonstrated that decreased fractional anisotropyin the limbic system especially in the columns of the fornix in presymptomatic and early symptomatic carriers ${ }^{94}$. Moreover, longitudinal studies also revealed an accelerated rate of atrophy in both medial temporal lobe and whole-brain volume measures. ${ }^{82,84}$
Several studies demonstrate that CSF A $\beta 42$ concentration in presymptomatic carriers of PS1 mutations are already profoundly low compared with a control group, when these subjects are 4 to 12 years younger than the ages at which their parents first developed symptoms of AD.$^{95,96}$ In addition, CSF total tau and p-tau levels are dramatically elevated in presymptomatic carriers of $P S 1$ or APP mutations compared with controls..$^{95,96}$ These findings support the concept that both $\mathrm{A} \beta 42$ and tau protein in CSF are sensitive indicators of presymptomatic EOFAD.

\section{Differential diagnosis and genetic counselling}

\subsection{Differential diagnosis}

Since several neurological heredity diseases can also present with some overlapping clinical features of EOFAD (e.g., early onset cognitive impairment and autosomal dominant pattern of inheritance), other differential diagnoses must be considered before the diagnosis of EOFAD is made. Frontotemporal dementia (FTD) is the third most common cause of early onset dementia, with $\mathrm{AD}$ and vascular dementia (VD) being the most common and second cause, respectively. ${ }^{2}$ Patients with an autosomal dominant pattern account for about 10-20\% of all FTD cases. ${ }^{97,98}$ Overall, patients with mutations in microtubuleassociated protein tau (MAPT) and progranulin (GRN) each account for $5-11 \%$ of total FTD cases ${ }^{97}$, and mutations in the C9ORF72 gene account for approximately another $11 \%$ of familial FTD cases ${ }^{99,100}$. Although behavioral variant FTD can present with memory and semantic impairment, it is more commonly characterized by insidious changes in personality, interpersonal conduct, and emotional modulation and involves progressive disintegration of the neural circuits involved in social cognition, emotion regulation, motivation, and decision making, which are clinical features that can distinguish from EOFAD. ${ }^{2,98}$ Usually, The FTD patients have frontal and/or temporal atrophy on MRI with appropriate changes on functional imaging. ${ }^{101}$ Furthermore, FDG-PET in most FTD patients often show an asymmetrically frontal and anterior temporal hypometabolism pattern, distinct from $\mathrm{AD}$ patients who have an abnormally low uptake in the posterior cingulate, precuneus, medial temporal lobe, and temporoparietal regions. ${ }^{101,102}$ In the United States, FDG-PET has been approved as a routine examination tool for the differential diagnosis of $\mathrm{AD}$ from FTD in 2004. ${ }^{102}$ PiB-PET can also be utilized for the differential diagnosis of EOFAD. A recent study demonstrated that $\mathrm{PiB}$ and FDG showed similar accuracy in discriminating AD and FTD, with PiB being more sensitive than FDG. ${ }^{103}$

Prion diseases (such as familial Creutzfeldt-Jakob disease (CJD), fatal familial insomnia) can also aggregate in families, and can share a number of clinical features with EOFAD. ${ }^{2,104}$ Familial prion disease are caused by mutations within the prion protein (PRNP) gene. ${ }^{104}$ Commonly, the patients with familial CJD have the codon 200 mutation, and fatal familial insomnia is associated with the codon 178 mutation in the PRNP. ${ }^{101}$ Clinically, familial CJD is characterized by cognitive impairment, along with myoclonus, periodic sharp-wave complexes in electroencephalogram (EEG), and hyperintensity in the cortex or striatum as shown by diffusion weighted imagesof MRI ${ }^{104}$ Furthermore, familial CJD usually has a more rapid progressive course than EOFAD. ${ }^{104}$ 
Since some types of EOFAD, such as $A P P$ mutations or duplications carriers, are commonly associated with cognitive impairment and a prominent CAA, certain familial types of vascular dementia, such as cerebral autosomal dominant arteriopathy with subcortical infarcts and leukoencephalopathy (CADASIL), should also be considered in the differential diagnosis. ${ }^{39,105}$ Hemorrhages or microhemorrhages occur more commonly in EOFAD than in CADASIL. ${ }^{39,78}$ In contrast, CAA of CADASIL usually causes leukoencephalopathy or ischemic stroke instead of hemorrhage. ${ }^{105}$ Ultimately, genetic testing can differentiate CADASIL from EOFAD, with the former being associated with Notch3 mutations. ${ }^{106}$

\subsection{Genetic diagnosis and genetic counselling}

\subsubsection{Diagnostic genetic testing}

Genetic testing for patients with early onset dementia and positive family history can be a valuable tool for identifying causative mutations and excluding some differential diagnoses. Sequencing the entire coding regions of $P S 1$ and $P S 2$, and exons 16 and 17 of the APP gene is required to determine if a pathogenic mutation exists. ${ }^{107}$ Genetic screening on 65 ADEOAD families revealed that $66 \%(\mathrm{~N}=43)$ were attributable to $P S 1$ mutations and $16 \%(\mathrm{~N}=10)$ to $A P P$ mutations, while $18 \%$ $(\mathrm{N}=12)$ remained unexplained as no mutation could be identified. ${ }^{107}$ Recently, whole genome single-nucleotide polymorphism (SNP) analysis was utilized to flag genomic regions of homozygosity identical by descent in two siblings with EOFAD with no identifiable $P S 1, P S 2$ or $A P P$ mutation and a family history suggestive of autosomal recessive inheritance. ${ }^{6}$ Several candidate loci were identified using this method and further sequencing analyses need to be done. ${ }^{6}$ Another study performed a large scale sequencing analysis of PS1, PS2, and $A P P$ genes in $>200$ unrelated patients with EOAD and discovered three novel and four previously identified PS1 mutations, one novel PS2 mutation and one novel APP mutation. ${ }^{108}$ Based on the segregation and association law, Guerreiro et al ${ }^{108}$ proposed a scale for grading mutations as not pathogenic, possibly pathogenic, probably pathogenic and definitely pathogenic.

\subsubsection{Presymptomatic genetic testing and counselling}

The availability of genetic testing and counseling is creating both advances and dilemmas for the asymptomatic relatives of an EOFAD individual with a pathogenic mutation. ${ }^{109-111}$ Prior to performing any genetic testing in asymptomatic individuals, the benefits of relieving anxiety and being able to make informed future decisions must be weighed against the potential risks of emotional distress, depression, compromise of insurance and employment, and social isolation through discussion with genetic counselor and a clinical geneticist as appropriate. ${ }^{112}$ Additionally, genetic testing and counseling should include a thorough assessment of family dynamics, financial support, and cultural issues. ${ }^{109}$ The issue of marital counselling and prenatal diagnosis must also be considered. ${ }^{109,110}$ Two independent studies have demonstrated that genetic testing and counseling in EOFAD can be completed successfully. Most presymptomatic individuals believe that testing is beneficial and demonstrate effective coping skills without major psychiatric complication during follow up observation. ${ }^{113,114}$ The most common reasons for presymptomatic family members to request genetic testing are concern about early symptoms of dementia, financial or family planning, and relief from anxiety. ${ }^{113,114}$

\section{Treatment}

To date, there are no large-scale clinical trials of EOFAD individuals to test the effect of the anti-dementia medicines due to the rarity of this population. Since the pathogenesis and clinical features are similar in EOFAD to those of sporadic AD, it has been common practice to use symptomatic drugs (such as donepezil, rivastigmine, galantamine and memantine) in managing EOFAD patients, which had been proven to ameliorate the symptoms of dementia in clinical trials of sporadic AD. ${ }^{115}$

Currently, several disease-modifying clinical trials based on the amyloid cascade hypothesis with an aim to reduce total brain $\mathrm{A} \beta$ load are ongoing in mild to moderate sporadic AD. ${ }^{115,116}$ Recently, the phase II trial of gantenerumab, a fully human antiA $\beta$ monoclonal antibody, showed amyloid-targeting antibody performed well resulting in a dose-dependent reduction in brain amyloid level in mild to moderate AD. ${ }^{116}$ However, it is now realized that initiating disease-modifying treatments during the dementia stage may not be adequate since extensive brain damage has already established; and thus, the maximal benefit of disease-modifying therapy should theoretically be obtained in the earlier stage. ${ }^{85,117}$ Disease-modifying prevention trials such as the Dominantly Inherited Alzheimer Network (DIAN), which target asymptomatic preclinical individuals, is already in the planning stages. ${ }^{7}$ The overarching preventive aim in preclinical stage of $\mathrm{AD}$ is to arrest the pathologic processes in the earliest stages (e.g., $A \beta$ deposition) in order to prevent subsequent neurodegeneration and eventual cognitive decline ${ }^{85,118}$ In the near future, presymptomatic EOFAD gene mutation carriers will have a potential to benefit from disease-modifying prevention.

\section{ACKNOWLEDGEMENTS}

National Nature Science Foundation of China (NSFC) [30700241 to Liyong Wu]; and the Beijing Scientific and Technological New Star Program [2007B069 to Liyong Wu]; Scholarship from Chinese Scholarship Council [to Liyong Wu]; Clinical fellowship from Pfizer Canada [to Liyong Wu]. Canadian institutes of Health Research (CIHR)[ MOP-11-51-31 to Pedro Rosa-Neto and Serge Gauthier]; Alzheimer's Association [NIRG-08-92090 to Pedro Rosa-Neto]; Nussia \& André Aisenstadt Foundation [to Pedro Rosa-Neto]; Fonds de la recherche en santé du Québec [16326 to Pedro Rosa-Neto]. Clinical Genetics Investigatorship by CIHR [to Ging-Yuek Hsiung].

\section{REFERENCES}

1. Feldman RG, Glaser GH, Chandler KA, Levy LL. Familial Alzheimers disease. Neurology. 1963;13:811-24.

2. Rossor MN, Fox NC, Mummery CJ, Schott JM, Warren JD. The diagnosis of young-onset dementia. Lancet Neurol. 2010;9: 793-806.

3. Campion D, Dumanchin C, Hannequin D, et al. Early-onset autosomal dominant Alzheimer disease: prevalence, genetic heterogeneity, and mutation spectrum. Am J Hum Genet. 1999; 65:664-70. 
4. Lleo A, Blesa R, Queralt R, et al. Frequency of mutations in the presenilin and amyloid precursor protein genes in early-onset Alzheimer disease in Spain. Arch Neurol. 2002;59:1759-63.

5. Janssen JC, Beck JA, Campbell TA, et al. Early onset familial Alzheimer's disease: mutation frequency in 31 families. Neurology. 2003;60:235-9.

6. Clarimon J, Djaldetti R, Lleo A, et al. Whole genome analysis in a consanguineous family with early onset Alzheimer's disease. Neurobiol Aging. 2009;30:1986-91.

7. Bateman RJ, Aisen PS, De Strooper B, et al. Autosomal-dominant Alzheimer's disease: a review and proposal for the prevention of Alzheimer's disease. Alzheimers Res Ther. 2011;2:35.

8. Albert MS, DeKosky ST, Dickson D, et al. The diagnosis of mild cognitive impairment due to Alzheimer's disease: recommendations from the National Institute on AgingAlzheimer's Association workgroups on diagnostic guidelines for Alzheimer's disease. Alzheimers Dement. 2011;7:270-9.

9. McKhann GM, Knopman DS, Chertkow H, et al. The diagnosis of dementia due to Alzheimer's disease: recommendations from the National Institute on Aging-Alzheimer's Association workgroups on diagnostic guidelines for Alzheimer's disease. Alzheimers Dement. 2011;7:263-9.

10. Sperling RA, Aisen PS, Beckett LA, et al. Toward defining the preclinical stages of Alzheimer's disease: recommendations from the National Institute on Aging-Alzheimer's Association workgroups on diagnostic guidelines for Alzheimer's disease. Alzheimers Dement. 2011;7:280-92.

11. St.George-Hyslop PH, Tanzi RE, Polinsky RJ, et al. The geneticdefect causing familial Alzheimers-disease maps on chromosome-21. Science. 1987;235:885-90.

12. Goate A, Chartierharlin MC, Mullan M, et al. Segregation of a missense mutation in the amyloid precursor protein gene with familial Alzheimers-disease. Nature. 1991;349:704-6.

13. St.George-Hyslop P, Haines J, Rogaev E, et al. Genetic-evidence for a novel familial Alzheimers-disease locus on chromosome14. Nat Genet. 1992;2:330-4

14. Mullan M, Houlden H, Windelspecht M, et al. A locus for familial early-onset Alzheimers-disease on the long arm of chromosome 14 , proximal to the alpha-1-antichymotrypsin gene. Nat Genet. 1992;2:340-2.

15. Schellenberg GD, Bird TD, Wijsman EM, et al. Genetic-linkage evidence for a familial Alzheimers-disease locus on chromosome-14. Science. 1992;258:668-71.

16. Sherrington R, Rogaev EI, Liang Y, et al. Cloning of a gene bearing missense mutations in early-onset familial Alzheimer's disease. Nature. 1995;375:754-60.

17. Rogaev EI, Sherrington R, Rogaeva EA, et al. Familial Alzheimer's disease in kindreds with missense mutations in a gene on chromosome 1 related to the Alzheimer's disease type 3 gene. Nature. 1995;376:775-8.

18. Levylahad E, Wasco W, Poorkaj P, et al. Candidate gene for the chromosome-1 familial Alzheimers-disease locus. Science. 1995;269:973-7.

19. Ikeuchi T, Kaneko H, Miyashita A, et al. Mutational analysis in early-onset familial dementia in the Japanese population. The role of PSEN1 and MAPT R406W mutations. Dement Geriatr Cogn Disord. 2008;26:43-9.

20. Kowalska A, Pruchnik-Wolinska D, Florczak J, et al. Genetic study of familial cases of Alzheimer's disease. Acta Biochim Pol. 2004;51:245-52

21. de la Torre JC. Three postulates to help identify the cause of Alzheimer's disease. J Alzheimers Dis. 2011;24:657-68.

22. Trojanowski JQ, Lee VM. Phosphorylation of paired helical filament tau in Alzheimer's disease neurofibrillary lesions: focusing on phosphatases. FASEB J. 1995;9:1570-6.

23. Glass CK, Saijo K, Winner B, Marchetto MC, Gage FH. Mechanisms underlying inflammation in neurodegeneration. Cell. 2010;140:918-34.

24. Hardy J, Selkoe DJ. The amyloid hypothesis of Alzheimer's disease: progress and problems on the road to therapeutics. Science. 2002;297:353-6
25. Bettens K, Sleegers K, Van Broeckhoven C. Current status on Alzheimer disease molecular genetics: from past, to present, to future. Hum Mol Genet. 2010;19:R4-R11.

26. Esler WP, Wolfe MS. A portrait of Alzheimer secretases--new features and familiar faces. Science. 2001;293:1449-54.

27. Citron M, Oltersdorf T, Haass C, et al. Mutation of the beta-amyloid precursor protein in familial Alzheimers-disease increases betaprotein production. Nature. 1992;360:672-4.

28. Suzuki N, Cheung TT, Cai XD, et al. An increased percentage of long amyloid beta protein secreted by familial amyloid beta protein precursor (beta APP717) mutants. Science. 1994;264: 1336-40.

29. Steiner H. Uncovering gamma-secretase. Curr Alzheimer Res. 2004; $1: 175-81$

30. Shepherd C, McCann H, Halliday GM. Variations in the neuropathology of familial Alzheimer's disease. Acta Neuropathol. 2009;118:37-52.

31. Gomez-Isla T, Growdon WB, McNamara MJ, et al. The impact of different presenilin 1 and presenilin 2 mutations on amyloid deposition, neurofibrillary changes and neuronal loss in the familial Alzheimer's disease brain: evidence for other phenotype-modifying factors. Brain. 1999;122(Pt 9):1709-19.

32. Lleo A, Berezovska O, Growdon JH, Hyman BT. Clinical, pathological, and biochemical spectrum of Alzheimer disease associated with PS-1 mutations. Am J Geriatr Psychiatry. 2004; 12:146-56.

33. Karlstrom H, Brooks WS, Kwok JB, et al. Variable phenotype of Alzheimer's disease with spastic paraparesis. J Neurochem. 2008;104:573-83.

34. Maarouf CL, Daugs ID, Spina S, et al. Histopathological and molecular heterogeneity among individuals with dementia associated with presenilin mutations. Mol Neurodegener. 2008; 3:20.

35. Brooks WS, Kwok JB, Kril JJ, et al. Alzheimer's disease with spastic paraparesis and 'cotton wool' plaques: two pedigrees with PS-1 exon 9 deletions. Brain. 2003;126:783-91.

36. Verkkoniemi A, Kalimo H, Paetau A, et al. Variant Alzheimer disease with spastic paraparesis: neuropathological phenotype. J Neuropathol Exp Neurol. 2001;60:483-92.

37. Dumanchin C, Tournier I, Martin C, et al. Biological effects of four PSEN1 gene mutations causing Alzheimer disease with spastic paraparesis and cotton wool plaques. Hum Mutat. 2006;27:1063.

38. Houlden H, Baker M, McGowan E, et al. Variant Alzheimer's disease with spastic paraparesis and cotton wool plaques is caused by PS- 1 mutations that lead to exceptionally high amyloid-beta concentrations. Ann Neurol. 2000;48:806-8.

39. Sleegers K, Brouwers N, Gijselinck I, et al. APP duplication is sufficient to cause early onset Alzheimer's dementia with cerebral amyloid angiopathy. Brain. 2006;129:2977-83.

40. Rovelet-Lecrux A, Hannequin D, Raux G, et al. APP locus duplication causes autosomal dominant early-onset Alzheimer disease with cerebral amyloid angiopathy. Nat Genet. 2006;38: 24-6.

41. Dermaut B, Kumar-Singh S, De Jonghe C, et al. Cerebral amyloid angiopathy is a pathogenic lesion in Alzheimer's disease due to a novel presenilin 1 mutation. Brain. 2001;124:2383-92.

42. Snider BJ, Norton J, Coats MA, et al. Novel presenilin 1 mutation (S170F) causing Alzheimer disease with Lewy bodies in the third decade of life. Arch Neurol. 2005;62:1821-30.

43. Singleton AB, Hall R, Ballard CG, et al. Pathology of early-onset Alzheimer's disease cases bearing the Thr113-114ins presenilin1 mutation. Brain. 2000;123 Pt 12:2467-74.

44. Mann DM, Pickering-Brown SM, Takeuchi A, Iwatsubo T. Amyloid angiopathy and variability in amyloid beta deposition is determined by mutation position in presenilin-1-linked Alzheimer's disease. Am J Pathol. 2001;158:2165-75.

45. Hendriks L, van Duijn CM, Cras P, et al. Presenile dementia and cerebral haemorrhage linked to a mutation at codon 692 of the beta-amyloid precursor protein gene. Nat Genet. 1992;1:218-21.

46. Rossi G, Giaccone G, Maletta R, et al. A family with Alzheimer disease and strokes associated with A713T mutation of the APP gene. Neurology. 2004;63:910-12. 
47. Piscopo P, Marcon G, Piras MR, et al. A novel PSEN2 mutation associated with a peculiar phenotype. Neurology. 2008;70: 1549-54.

48. Ishikawa A, Piao YS, Miyashita A, et al. A mutant PSEN1 causes dementia with Lewy bodies and variant Alzheimer's disease. Ann Neurol. 2005;57:429-34.

49. Balasa M, Gelpi E, Antonell A, et al. Clinical features and APOE genotype of pathologically proven early-onset Alzheimer disease. Neurology. 2011;76:1720-5.

50. Mullan M, Houlden H, Crawford F, Kennedy A, Rogues P, Rossor M. Age-of-onset in familial early-onset Alzheimers-disease correlates with genetic etiology. Am J Med Genet. 1993;48: 129-30.

51. Wijsman EM, Daw EW, Yu X, et al. APOE and other loci affect ageat-onset in Alzheimer's disease families with PS2 mutation. Am J Med Genet B Neuropsychiatr Genet. 2005;132B:14-20.

52. Jacobs D, Sano M, Marder K, et al. Age at onset of Alzheimer's disease: relation to pattern of cognitive dysfunction and rate of decline. Neurology. 1994;44:1215-20.

53. Koedam EL, Lauffer V, van der Vlies AE, van der Flier WM, Scheltens P, Pijnenburg YA. Early-versus late-onset Alzheimer's disease: more than age alone. J Alzheimers Dis. 2010;19:1401-8.

54. Bird TD, Sumi SM, Nemens EJ, et al. Phenotypic heterogeneity in familial Alzheimers-disease - a study of 24 kindreds. Ann Neurol. 1989;25:12-25

55. Larner AJ, Doran M. Clinical phenotypic heterogeneity of Alzheimer's disease associated with mutations of the presenilin1 gene. J Neurol. 2006;253:139-58.

56. Lopera F, Ardilla A, Martinez A, et al. Clinical features of earlyonset Alzheimer disease in a large kindred with an E280A presenilin-1 mutation. JAMA. 1997;277:793-9.

57. Rudzinski LA, Fletcher RM, Dickson DW, et al. Early onset familial Alzheimer disease with spastic paraparesis, dysarthria, and seizures and N135S mutation in PSEN1. Alzheimer Dis Assoc Dis. 2008;22:299-307.

58. Jayadev S, Leverenz JB, Steinbart E, et al. Alzheimer's disease phenotypes and genotypes associated with mutations in presenilin 2. Brain. 2010;133:1143-54.

59. Kennedy AM, Newman S, McCaddon A, et al. Familial Alzheimers-disease - a pedigree with a mis-sense mutation in the amyloid precursor protein gene (amyloid precursor protein 717 valine --> glycine). Brain. 1993;116:309-24.

60. Cabrejo L, Guyant-Marechal L, Laquerriere A, et al. Phenotype associated with APP duplication in five families. Brain. 2006; 129:2966-76

61. Jia JP, Xu E, Shao YK, Jia JM, Sun YX, Li D. One novel presenilin1 gene mutation in a Chinese pedigree of familial Alzheimer's disease. J Alzheimers Dis. 2005;7:119-24.

62. Janssen JC, Hall M, Fox NC, et al. Alzheimer's disease due to an intronic presenilin-1 (PSEN1 intron 4) mutation: a clinicopathological study. Brain. 2000;123(Pt 5):894-907.

63. Acosta-Baena N, Sepulveda-Falla D, Lopera-Gomez CM, et al. Predementia clinical stages in presenilin 1 E280A familial earlyonset Alzheimer's disease: a retrospective cohort study. Lancet Neurol. 2011;10:213-20.

64. Filley CM, Rollins YD, Anderson CA, et al. The genetics of very early onset Alzheimer disease. Cogn Behav Neurol. 2007;20: 149-56.

65. Arai N, Kishino A, Takahashi Y, et al. Familial cases presenting very early onset autosomal dominant Alzheimer's disease with I143T in presenilin- 1 gene: implication for genotype-phenotype correlation. Neurogenetics. 2008;9:65-7.

66. Goldman JS, Reed B, Gearhart R, Kramer JH, Miller BL. Very early-onset familial Alzheimer's disease: a novel presenilin 1 mutation. Int J Geriat Psychiatry. 2002;17:649-51.

67. Ataka S, Tomiyama $\mathrm{T}$, Takuma $\mathrm{H}$, et al. A novel presenilin-1 mutation (Leu85Pro) in early-onset Alzheimer disease with spastic paraparesis. Arch Neurol. 2004;61:1773-6.

68. Jimenez-Escrig A, Rabano A, Guerrero C, et al. New V272A presenilin 1 mutation with very early onset subcortical dementia and parkinsonism. Eur J Neurol. 2004;11:663-9.
69. Lampe TH, Bird TD, Nochlin D, et al. Phenotype of chromosome 14-linked familial Alzheimers-disease in a large kindred. Ann Neurol. 1994;36:368-78.

70. Gomez-Tortosa E, Barquero S, Baron M, et al. Clinical-genetic correlations in familial Alzheimer's disease caused by presenilin 1 mutations. J Alzheimers Dis. 2010;19:873-84.

71. Crook R, Verkkoniemi A, Perez-Tur J, et al. A variant of Alzheimer's disease with spastic paraparesis and unusual plaques due to deletion of exon 9 of presenilin 1. Nat Med. 1998; 4:452-5

72. Sodeyama $\mathrm{N}$, Iwata $\mathrm{T}$, Ishikawa $\mathrm{K}$, et al. Very early onset Alzheimer's disease with spastic paraparesis associated with a novel presenilin 1 mutation (Phe237Ile). J Neurol Neurosurg Psychiatry. 2001;71:556-7.

73. Ezquerra M, Lleo A, Castellvi M, et al. A novel mutation in the PSEN2 gene (T430M) associated with variable expression in a family with early-onset Alzheimer disease. Arch Neurol. 2003; 60:1149-51.

74. Cras P, van Harskamp F, Hendriks L, et al. Presenile Alzheimer dementia characterized by amyloid angiopathy and large amyloid core type senile plaques in the APP 692Ala-->Gly mutation. Acta Neuropathol. 1998;96:253-60.

75. Roks G, Van Harskamp F, De Koning I, et al. Presentation of amyloidosis in carriers of the codon 692 mutation in the amyloid precursor protein gene (APP692). Brain. 2000;123(Pt 10): 2130-40.

76. Brooks WS, Kwok JB, Halliday GM, et al. Hemorrhage is uncommon in new Alzheimer family with Flemish amyloid precursor protein mutation. Neurology. 2004;63:1613-17.

77. Levy E, Carman MD, Fernandez-Madrid IJ, et al. Mutation of the Alzheimer's disease amyloid gene in hereditary cerebral hemorrhage, Dutch type. Science. 1990;248:1124-6.

78. Basun $\mathrm{H}$, Bogdanovic $\mathbf{N}$, Ingelsson $\mathbf{M}$, et al. Clinical and neuropathological features of the Arctic APP gene mutation causing early-onset Alzheimer disease. Arch Neurol. 2008;65: 499-505.

79. Grabowski TJ, Cho HS, Vonsattel JP, Rebeck GW, Greenberg SM. Novel amyloid precursor protein mutation in an Iowa family with dementia and severe cerebral amyloid angiopathy. Ann Neurol. 2001;49:697-705.

80. Bornebroek M, Haan J, Maat-Schieman ML, Van Duinen SG, Roos RA. Hereditary cerebral hemorrhage with amyloidosis-Dutch type (HCHWA-D): I--A review of clinical, radiologic and genetic aspects. Brain Pathol. 1996;6:111-14.

81. Kasuga K, Shimohata T, Nishimura A, et al. Identification of independent APP locus duplication in Japanese patients with early-onset Alzheimer disease. J Neurol Neurosurg Psychiatry. 2009;80:1050-2

82. Ridha BH, Barnes J, Bartlett JW, et al. Tracking atrophy progression in familial Alzheimer's disease: a serial MRI study. Lancet Neurol. 2006;5:828-34.

83. Quiroz YT, Budson AE, Celone K, et al. Hippocampal hyperactivation in presymptomatic familial Alzheimer's disease. Ann Neurol. 2010;68:865-75

84. Chan D, Janssen JC, Whitwell JL, et al. Change in rates of cerebral atrophy over time in early-onset Alzheimer's disease: longitudinal MRI study. Lancet. 2003;362:1121-2.

85. Wu L, Rosa-Neto P, Gauthier S. Use of biomarkers in clinical trials of Alzheimer disease: from concept to application. Mol Diagn Ther. 2011;15:313-25.

86. Klunk WE, Price JC, Mathis CA, et al. Amyloid deposition begins in the striatum of presenilin-1 mutation carriers from two unrelated pedigrees. J Neurosci. 2007;27:6174-84.

87. Villemagne VL, Ataka S, Mizuno T, et al. High striatal amyloid beta-peptide deposition across different autosomal Alzheimer disease mutation types. Arch Neurol. 2009;66:1537-44.

88. Knight WD, Okello AA, Ryan NS, et al. Carbon-11-Pittsburgh compound B positron emission tomography imaging of amyloid deposition in presenilin 1 mutation carriers. Brain. 2011;134: 293-300. 
89. Remes AM, Laru L, Tuominen $\mathrm{H}$, et al. Carbon 11-labeled Pittsburgh compound B positron emission tomographic amyloid imaging in patients with APP locus duplication. Arch Neurol. 2008;65:540-4.

90. Mosconi L, Sorbi S, de Leon MJ, et al. Hypometabolism exceeds atrophy in presymptomatic early-onset familial Alzheimer's disease. J Nucl Med. 2006:47:1778-86.

91. Ringman JM, Medina LD, Braskie M, et al. Effects of risk genes on BOLD activation in presymptomatic carriers of familial Alzheimer's disease mutations during a novelty encoding task. Cereb Cortex. 2011;21:877-83.

92. Fox NC, Warrington EK, Freeborough PA, et al. Presymptomatic hippocampal atrophy in Alzheimer's disease. A longitudinal MRI study. Brain. 1996;119(Pt 6):2001-7.

93. Schott JM, Fox NC, Frost C, et al. Assessing the onset of structural change in familial Alzheimer's disease. Ann Neurol. 2003;53: 181-8.

94. Ringman JM, O'Neill J, Geschwind D, et al. Diffusion tensor imaging in preclinical and presymptomatic carriers of familial Alzheimer's disease mutations. Brain. 2007;130:1767-76.

95. Moonis M, Swearer JM, Dayaw MP, et al. Familial Alzheimer disease: decreases in CSF Abeta42 levels precede cognitive decline. Neurology. 2005;65:323-5.

96. Ringman JM, Younkin SG, Pratico D, et al. Biochemical markers in persons with preclinical familial Alzheimer disease. Neurology. 2008;71:85-92.

97. Rohrer JD, Guerreiro R, Vandrovcova J, et al. The heritability and genetics of frontotemporal lobar degeneration. Neurology. 2009; 73:1451-6.

98. Piguet O, Hornberger M, Mioshi E, Hodges JR. Behaviouralvariant frontotemporal dementia: diagnosis, clinical staging, and management. Lancet Neurol. 2011;10:162-72.

99. Dejesus-Hernandez M, Mackenzie IR, Boeve BF, et al. Expanded GGGGCC hexanucleotide repeat in noncoding region of C9ORF72 causes chromosome 9p-linked FTD and ALS. Neuron. 2011;72:245-56.

100.Renton AE, Majounie E, Waite A, et al. A hexanucleotide repeat expansion in C9ORF72 is the cause of chromosome 9p21-linked ALS-FTD. Neuron. 2011;72:257-68.

101.Panegyres PK, Frencham K. Course and causes of suspected dementia in young adults: a longitudinal study. Am J Alzheimers Dis Other Dement. 2007;22:48-56.

102.Laforce R, Jr., Buteau JP, Paquet N, Verret L, Houde M, Bouchard RW. The value of PET in mild cognitive impairment, typical and atypical/unclear dementias: a retrospective memory clinic study. Am J Alzheimers Dis Other Dement. 2010;25:324-32.

103. Rabinovici GD, Rosen HJ, Alkalay A, et al. Amyloid vs FDG-PET in the differential diagnosis of AD and FTLD. Neurology. 2011; 77:2034-42.

104.Gambetti P, Parchi P, Chen SG. Hereditary Creutzfeldt-Jakob disease and fatal familial insomnia. Clin Lab Med. 2003;23: 43-64.
105. Dichgans M, Mayer M, Uttner I, et al. The phenotypic spectrum of CADASIL: clinical findings in 102 cases. Ann Neurol. 1998;44: 731-9.

106. Joutel A, Corpechot C, Ducros A, et al. Notch3 mutations in CADASIL, a hereditary adult-onset condition causing stroke and dementia. Nature. 1996;383:707-10.

107. Raux G, Guyant-Marechal L, Martin C, et al. Molecular diagnosis of autosomal dominant early onset Alzheimer's disease: an update. J Med Genet. 2005;42:793-5.

108. Guerreiro RJ, Baquero M, Blesa R, et al. Genetic screening of Alzheimer's disease genes in Iberian and African samples yields novel mutations in presenilins and APP. Neurobiol Aging. 2010; 31:725-31.

109. Goldman JS, Hou CE. Early-onset Alzheimer disease: when is genetic testing appropriate? Alzheimer Dis Assoc Disord. 2004; 18:65-7.

110. Butler R, Dwosh E, Beattie BL, et al. Genetic counseling for earlyonset familial Alzheimer disease in large Aboriginal kindred from a remote community in British Columbia: unique challenges and possible solutions. J Genet Couns. 2011;20: $136-42$.

111. Patterson C, Feightner JW, Garcia A, Hsiung GY, MacKnight C, Sadovnick AD. Diagnosis and treatment of dementia: 1. Risk assessment and primary prevention of Alzheimer disease. CMAJ. 2008;178:548-56.

112. Bird TD, Bennett RL. Why do DNA testing? Practical and ethical implications of new neurogenetic tests. Ann Neurol. 1995;38: 141-6.

113. Steinbart EJ, Smith CO, Poorkaj P, Bird TD. Impact of DNA testing for early-onset familial Alzheimer disease and frontotemporal dementia. Arch Neurol. 2001;58:1828-31.

114. Fortea J, Llado A, Clarimon J, et al. PICOGEN: Five years experience with a genetic counselling program for dementia. Neurologia. 2011;26:143-9.

115. Mangialasche F, Solomon A, Winblad B, Mecocci P, Kivipelto M. Alzheimer's disease: clinical trials and drug development. Lancet Neurol. 2010;9:702-16.

116. Ostrowitzki S, Deptula D, Thurfjell L, et al. Mechanism of amyloid removal in patients with Alzheimer disease treated with gantenerumab. Arch Neurol. 2012; vol 69, pp. 198-207.

117. Aisen PS, Andrieu S, Sampaio C, et al. Report of the task force on designing clinical trials in early (predementia) AD. Neurology. 2011;76:280-6

118. Cummings JL, Doody R, Clark C. Disease-modifying therapies for Alzheimer disease: challenges to early intervention. Neurology. 2007;69:1622-34. 